American Journal of Infectious Diseases 3 (4): 267-275, 2007

ISSN 1553-6203

(C) 2007 Science Publications

\title{
Induction of a Soluble Anti-HIV-1 factor (s) with IFN- $\gamma$, IL-10, and $\beta$-Chemokine Modulating Activity by an Influenza-Bacterial Polyantigenic Mixture
}

\author{
José W. Rodríguez, ${ }^{1}$ Nat O. Pagan, ${ }^{1}$ María C. Ocasio, ${ }^{1}$ Zilka Ríos, ${ }^{1}$ Luis A. Cubano, \\ ${ }^{1}$ Nawal M. Boukli, ${ }^{1}$ Miguel Otero, ${ }^{1}$ Robert Hunter, ${ }^{2}$ Madhavan P. Nair, ${ }^{3}$ and Eddy Rios-Olivares ${ }^{1}$ \\ Department of ${ }^{1}$ Microbiology and Immunology and ${ }^{2}$ Internal Medicine, Universidad Central del Caribe \\ School of Medicine, Bayamón, Puerto Rico, ${ }^{3}$ Department of Immunology, Florida International \\ University College of Medicine, Miami, Florida
}

\begin{abstract}
Partial immune restoration may be obtained with highly active antiretroviral therapy (HAART), but specific anti-HIV-1 immune responses do not appear to improve substantially. We have demonstrated that a soluble factor(s) induced by a mixture of inactivated influenza and bacterial vaccines called polyantigenic immunomodulator (PAI), possesses strong immunoregulatory and antiHIV-1 activities. In the present study, we show that culture fluids from both PAI-stimulated peripheral blood mononuclear cells (PBMC) and CD8+ T-cells of HIV-1 infected patients were able to suppress HIV-1 replication in an MHC-unrestricted fashion. The PAI-induced antiviral activity was eliminated when culture fluids were pre-heated at $100^{\circ} \mathrm{C}$ for $10 \mathrm{~min}$. and it is associated with induction of IFN- $\gamma$, MIP-1 $\alpha$, MIP-1 $\beta$, and RANTES production, but inhibition of IL-10. Furthermore, this induction is dependent on the immunological status (CD4:CD8 ratio) of the HIV-1 infected patient. Taken together, our results suggest that the MHC-unrestricted HIV-1 suppression that is induced by culture fluids from PAI-stimulated PBMC may result from the stimulation of immune cell subpopulations to produce a heat-labile antiviral soluble factor(s), which in turn modulate cytokine and $\beta$-chemokine production. The identification of this PAI-induced soluble factor(s) may have major therapeutic potential.
\end{abstract}

Key words: Human Immunodeficiency virus-1 (HIV-1); polyantigenic immunomodulator (PAI); antiviral activity; cytokines; $\beta$-chemokines

\section{INTRODUCTION}

The HIV/AIDS epidemic has already claimed over 20 million lives. Estimates suggest that a cumulative global total of 38.6 (33.4 - 46.0) million people will have been infected with HIV-1 by the end of $2005^{[1]}$. It is now widely accepted that restoration of immune functions using highly active antiretroviral therapy (HAART) is insufficient ${ }^{[2-4]}$ and that novel therapeutic immunization strategies are urgently needed to strengthen HAART in the treatment of HIV-1 disease [5].

Discovery of a safe, inexpensive and effective HIV-1 immunotherapy to be used in combination with the current antiretroviral therapy seems to be one of the most promising solutions to resolving this global problem. The ideal candidate should suppress HIV-1 replication effectively without generating additional impairment to the immune response, such as undue activation of CD4+ and CD8+ T-cells, apoptosis or anergy ${ }^{[6]}$. Several studies have reported antiviral inducing capacity of HIV-1 antigens in clinical trials when used alone or combined with HAART ${ }^{[7-14]}$. The effect of these antigens is primarily on modulating HIV-1-specific CD4+ and CD8+ T-cell immune responses.

The identification of anti-HIV-1 soluble factors may have major therapeutic potential. At present, several soluble factors have been identified that possess anti-HIV-1 activity. They include CD8 antiviral factor (CAF), $\beta$-chemokines, stromal cell-derived factor-1 (SDF-1)/CXCL12, eosinophils-derived neurotoxin (EDN), amino-terminal fragment of urokinase-type plasminogen activator (ATF-uPA), IL-16, antithrombin

Corresponding Author: José W. Rodríguez, Department of Microbiology and Immunology, Universidad Central del Caribe School of Medicine, P.O. Box 60327, Bayamón, Puerto Rico 00960 
III (ATIII), $\alpha$-Defensins, I-309, peroxiredoxin, TNF- $\alpha$, IL-13, IFN- $\gamma / \alpha$, macrophage-derived chemokine (MDC), leukemia inhibitor factor (LIF), APOBEC family, and TRIM5alpha ${ }^{[15-17]}$.

CAF was the first reported anti-HIV-1 soluble factor ${ }^{[18-20]}$ and it can block HIV-1 replication by inhibiting long terminal repeat (LTR)-driven transcription ${ }^{[21]}$. $\beta$-Chemokines (MIP-1 $\alpha$, MIP-1 $\beta$, and RANTES) suppress the entry of HIV-1 by blocking the CCR5 co-receptor $\left.{ }^{22,}{ }^{23}\right]$. SDF-1/CXCL12 also suppresses the entry of HIV-1 but by blocking the CXCR4 co-receptor ${ }^{[24]}$. EDN blocks HIV-1 replication prior reverse transcription ${ }^{[25]}$. ATF-uPA interferes with the budding and assembly steps of $\mathrm{HIV}-1$ replication through receptor-mediated pathways ${ }^{[26]}$. IL-16 exerts anti-HIV-1 activity by blocking viral entry via CD4, or through reduction of multiple co-receptors on the surface of the target cells ${ }^{[27]}$. ATIII has the ability to block NF-KB activation, a molecule involved in HIV-1 replication ${ }^{[28]}$. Alpha-defensins (produced by neutrophils) inhibit HIV-1 infection following viral entry, but are not involved in the inhibition of HIV-1 gene expression and LTR activation ${ }^{[29]}$. Chemokine I309 is a ligand able to block X4 HIV-1 strains by blocking the CCR8 co-receptor ${ }^{[30]}$. The peroxiredoxin family (natural killer enhancing factors) inhibits both R5 and X4 viruses through the down-regulation of the NF-KB pathway that blocks HIV-1 LTR transcription [31]. IL-13 and TNF- $\alpha$ inhibit HIV-1 replication in macrophages by down-regulating the surface expression of CD4, CCR5 and CXCR4 ${ }^{[32]}$ and by blocking reverse transcription ${ }^{[33]}$. IFN- $\gamma$ inhibits HIV-1 LTR activation whereas IFN- $\alpha$ inhibits HIV-1 through JAK/STAT pathways ${ }^{[34]}$. MDC (produced by macrophages) and LIF (produced by CD8+ T-cells) blocks both R5 and X4 virus before transcription ${ }^{[35,36]}$. Recently, two intracellular factors were identified with antiretroviral activity, the APOBEC family and TRIM5alpha. The APOBEC family members are cytosine deaminases that deaminate deoxycytosine (dC) to form deoxyuracil (dU) on newly synthesized minusstrand viral cDNAs causing guanosine $(G)$ to adenosine (A) mutations on the plus-strand DNA and stopping viral replication ${ }^{[37]}$. Moreover, TRIM5 $\alpha$ is a trimeric molecule that interacts with hexameric viral capsids forming TRIM5 $\alpha$-virus complexes that lead to an early block of viral replication before the virus has had the opportunity to reverse transcribe ${ }^{[38]}$.

During the last twenty-six years, and as an alternative to the above approaches, we have characterized a biological response modifier known as polyantigenic immunomodulator (PAI) that acts as a non-specific modulator of the immune response. PAI, which consists of a mixture of influenza and bacterial inactivated vaccines, is able to induce immunoregulatory effects in both human and animal models. The effects of PAI include: (a) tumor regression in mice ${ }^{[39]}$, (b) cytotoxic activity against tumor cell lines ${ }^{[40]}$, (c) enhanced lymphoproliferative responses in humans with cancer ${ }^{[41]}$, (d) delayed disease progression and improvement of immunologic response in HIV-infected subjects ${ }^{[42,43]}$, (e) suppression of viral replication and regulation of cytokine production in $\mathrm{HIV}$-infected peripheral blood mononuclear cells (PBMC) ${ }^{[44]}$, and (f) reduced proliferative responses in HIV-infected PBMC ${ }^{[45]}$. We believe that the most likely mechanism by which PAI exerts its anti-HIV-1 effect is by stimulating a wide range of immune cell subpopulations to produce antiHIV-1 soluble factor(s).

In the present study, we demonstrated that PAI induces a soluble factor(s) capable of suppressing HIV1 replication and modulating IFN- $\gamma$, IL-10, and $\beta$ chemokines. We also showed that both PBMC and CD8+ T-cells are responsible for the observed antiHIV-1 activity. Furthermore, we showed that the generation of this anti-HIV-1 activity was affected by high temperature and the immunological status (CD4:CD8 ratio) of the HIV-1 infected patients.

\section{MATERIALS AND METHODS}

Participants: One symptomatic and four asymptomatic HIV-1 seropositive patients were recruited through the HIV-1 Registry of the Universidad Central del Caribe School of Medicine/Ramón Ruiz Arnau University Hospital at Bayamón, Puerto Rico. Patients were demonstrated to be HIV-1 seropositive as defined by the presence of anti-HIV-1 antibodies detected by ELISA (Organon Teknika Corp., Durham, NC) and HIV-1 RNA RT-PCR (Roche Diagnostics, Indianapolis, IN). HIV-1 seronegative healthy volunteers also donated blood for this study. These patients were not under antiretroviral treatment. This study was conducted using institutional review boardapproved protocols.

Determination of CD4:CD8 ratio: Flow cytometric analysis was performed on peripheral blood samples collected in the presence of EDTA and prepared utilizing a lysed whole blood method, standardized for use in a FACSCalibur instrument (BD Biosciences, San Jose, CA). Samples were stained for $15 \mathrm{~min}$ in the dark at room temperature with matching combinations of monoclonal antibodies directly conjugated with FITC 
or PE (BD Biosciences, San Diego, CA). The panel used for two-color immunophenotyping included markers: CD3-FITC/CD4-PE and CD3-FITC/CD8-PE in order to determine $\mathrm{CD} 4: \mathrm{CD} 8$ ratios.

Preparation of PAI: PAI is a mixture of two FDAapproved inactivated vaccines. It consists of a mixture of Influenza type A and B vaccine (Connaught Laboratories, Swiftwater, PA) and a mixed respiratory vaccine (Miles, Spokane, WA) that contains Staphylococcus aureus, Streptococcus (viridians and non-hemolytic), Streptococcus pneumoniae, Moraxella catharralis, Klebsiella pneumoniae, and Haemophilus influenzae. PAI was prepared by mixing these two vaccines $1: 1$ by volume. PAI was further diluted with tissue culture medium to $1: 10,000$, which has been shown in vitro to be the most effective working dilution [45].

Isolation and culture of PBMC: PBMC from HIV-1 seronegative healthy volunteers and HIV-1 seropositive patients were prepared from fresh heparinized peripheral whole blood on Ficoll-Histopaque (Sigma, St. Louis, MO) gradients. Blood was centrifuged at $1,500 \mathrm{rpm}$ for $15 \mathrm{~min}$. Following centrifugation, buffy coat was collected and diluted at 1:1 with phosphate buffer saline (PBS) (Invitrogen, Gaithersburg, MD) at room temperature. Ficoll-Histopaque was added by submerging the pipette into the diluted buffy coat. Samples were centrifuged at $1,500 \mathrm{rpm}$ for $30 \mathrm{~min}$. at room temperature. The PBMC layer was collected and cells were washed once with PBS. Total cell numbers and cell viabilities (90-95\%) were determined by trypan blue exclusion (Sigma, St. Louis, MO) in a hemocytometer counting chamber. PBMC were resuspended in culture medium containing RPMI 1640 (Life Technologies, Gaithersburg, MD), 25mM HEPES (Sigma, St. Louis, MO), 2 mM glutamine (Sigma, St. Louis, MO), $100 \mu \mathrm{g}$ streptomycin (Sigma, St. Louis, MO), $100 \mathrm{U}$ penicillin (Sigma, St. Louis, MO), and $10 \%$ fetal bovine serum (Life Technologies, Gaithersburg, MD). In other experiments, CD8+ T-cells were separated from PBMC using the CD8 negative isolation kit (Dynal, Lake Success, NY) and tested for their capacity to generate anti-HIV-1 activity. After selection, the purity was $80-90 \%$ as determined by flow cytometry.

Isolation and culture of PBMC: PBMC from HIV-1 seronegative healthy volunteers and HIV-1 seropositive patients were prepared from fresh heparinized peripheral whole blood on Ficoll-Histopaque (Sigma, St. Louis, MO) gradients. Blood was centrifuged at
1,500 rpm for $15 \mathrm{~min}$. Following centrifugation, buffy coat was collected and diluted at 1:1 with phosphate buffer saline (PBS) (Invitrogen, Gaithersburg, MD) at room temperature. Ficoll-Histopaque was added by submerging the pipette into the diluted buffy coat. Samples were centrifuged at $1,500 \mathrm{rpm}$ for $30 \mathrm{~min}$. at room temperature. The PBMC layer was collected and cells were washed once with PBS. Total cell numbers and cell viabilities (90-95\%) were determined by trypan blue exclusion (Sigma, St. Louis, MO) in a hemocytometer counting chamber. PBMC were resuspended in culture medium containing RPMI 1640 (Life Technologies, Gaithersburg, MD), 25mM HEPES (Sigma, St. Louis, MO), 2 mM glutamine (Sigma, St. Louis, MO), $100 \mu \mathrm{g}$ streptomycin (Sigma, St. Louis, MO), 100 U penicillin (Sigma, St. Louis, MO), and $10 \%$ fetal bovine serum (Life Technologies, Gaithersburg, MD). In other experiments, CD8+ T-cells were separated from PBMC using the CD8 negative isolation kit (Dynal, Lake Success, NY) and tested for their capacity to generate anti-HIV-1 activity. After selection, the purity was $80-90 \%$ as determined by flow cytometry.

Stimulation of PBMC with PAI: PBMC (3 x $\left.10^{6} / \mathrm{ml}\right)$ were stimulated with PAI for 3 days and used as antiHIV-1 soluble factor-producing cells. After incubation, PBMC $\left(3 \times 10^{6} / \mathrm{ml}\right)$ were washed and incubated in 10 $\mathrm{ml}$ of PAI-free culture media and maintained at $37^{\circ} \mathrm{C}$ in an atmosphere containing $5 \% \mathrm{CO}_{2}$ for 21 days. Every three days, $10 \mathrm{ml}$ of culture fluids were collected, filtered, and replaced with $10 \mathrm{ml}$ of fresh PAI-free culture medium. PBMC cultured in the absence of stimulation were used as controls in each experiment. The anti-HIV-1 activity of these culture fluids was tested on in vitro acutely $\mathrm{HIV}-1_{\mathrm{SF} 2}$ infected $\mathrm{PBMC}$ from healthy volunteers. The concentration of culture fluid used in all experiments was $40 \%$ ( $\mathrm{vol} / \mathrm{vol})$. In other experiments the culture fluids were heated prior to testing their anti-HIV-1 activity. Two heat treatments were used: one was at $56^{\circ} \mathrm{C}$ for $30 \mathrm{~min}$ and the other was at $100^{\circ} \mathrm{C}$ for $10 \mathrm{~min}$.

HIV-1 inhibition assay: Isolated PBMC from HIV-1 seronegative healthy volunteers were acutely infected with the HIV-1 $1_{\mathrm{SF} 2}\left(1,000 \mathrm{TCID}_{50} / 10^{5}\right.$ cells $)$ strain and used as target cells. HIV-1 $1_{\mathrm{SF} 2}$ is an excellent strain since it utilizes either CXCR4 (R4) or CCR5 (R5) coreceptors for viral entry. PBMC $\left(10 \times 10^{6} / \mathrm{ml}\right)$ were suspended in $100 \mu \mathrm{l}$ of culture medium and pre-treated with polybrene $(2 \mu \mathrm{g} / \mathrm{ml})$ for $30 \mathrm{~min}$ followed by 90 min of viral absorption at $37^{\circ} \mathrm{C}$. After infection, cells were washed twice with PBS to remove unabsorbed 
virus. HIV-1-infected PBMC $\left(\begin{array}{llll}1 & \mathrm{x} & 10^{6} / \mathrm{ml}\end{array}\right)$ were harvested in $2.5 \mathrm{ml}$ of PAI-free culture media. Cells were fed with $1 \mathrm{ml}$ of fresh PAI-free culture medium and $1 \mathrm{ml}$ of culture fluid from PAI-stimulated PBMC of each HIV-1 seropositive patient every three days for 21 days. Supernatants $(2 \mathrm{ml})$ of these cultures were collected every three days until 21 days post-infection, frozen at $-135^{\circ} \mathrm{C}$, and tested for $\mathrm{HIV}-1$ p24 protein using HIV-1 p24-ELISA (NEN Life Science Products, Inc., Boston, MA).

Measurement of cytokine/ $\beta$-chemokine production after in vitro PAI stimulation: Cytokine (IL-2, IL-4, IFN- $\gamma$, IL-10 [BDPharmingen, San Diego, CA] and $\beta$ chemokine (MIP-1 $\alpha$, MIP-1 $\beta$, and RANTES [Biosource International, Camarillo, CA]) levels from the culture fluids were determined by ELISA.

Statistical analysis: Data was collected and statistically analyzed using SPSS version 14.0 software package (SPSS, Chicago, IL). Student's $t$-test and chi-square tests were used to compare significance between group means and standard deviations. All significant levels that were used for testing statistical significant differences were two-tailed with a $\mathrm{p}$-value $=<0.05$.

\section{RESULTS}

Inhibition of HIV-1 replication by culture fluids from PAI-stimulated PBMC: The effect of fluids from unstimulated (control) or stimulated (with PAI) PBMC cultures was tested in cells acutely infected with HIV-1 $1_{\mathrm{SF} 2}$ virus. The culture fluids of PAI-stimulated PBMC, from a HIV-1 infected patient, inhibited HIV-1 replication in PBMC infected with HIV-1 $1_{\mathrm{SF} 2}$ virus (Fig. 1A). Inhibition of HIV-1 replication was also observed in cultured fluids of PAI-stimulated CD8+ T-cells from the same patient (Fig. 1B). These latter experiments were performed to determine whether PAI-stimulated CD8+ T-cells were responsible for producing anti-HIV1 factor(s). The data demonstrates that both PAIstimulated PBMC and CD8+ T-cells can generate antiviral activity. Extents of inhibition were $97 \%$ and $68 \%$, respectively. The minimum inhibitory dose concentration of PAI-stimulated culture fluids was at $40 \%$ ( $\mathrm{vol} / \mathrm{vol}$ ). To assess possible toxic effects due to exposure of HIV-1 infected PBMC to PAI-stimulated culture fluids, we measured the viability of cultures by trypan blue exclusion. No significant differences in the viability of HIV-1 infected PBMC with or without PAIstimulated culture fluids were observed (data not shown).

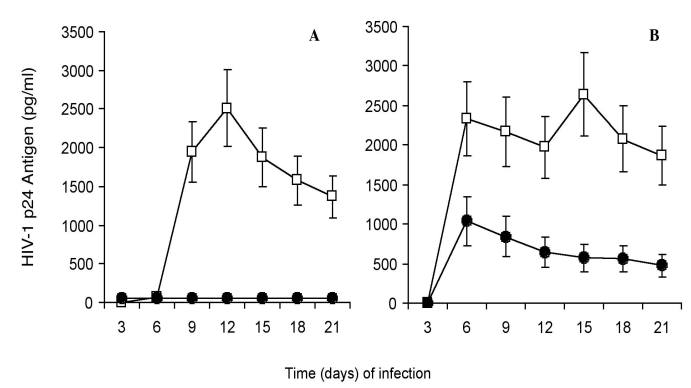

Fig. 1: Inhibition of HIV-1 replication by culture fluids derived from PAI-stimulated PBMC (A) and CD8+ T-cells (B) of a HIV-1 seropositive patient. Acutely infected PBMC from healthy volunteers with $\mathrm{HIV}-1_{\mathrm{SF} 2}$ virus $(1,000$ $\mathrm{TCID}_{50} / 10^{5}$ cells) and cultured with $40 \%$ of culture fluids from PBMC or CD8+ T-cells stimulated with PAI (circles) or unstimulated (open squares). Supernatants derived from HIV-1 infected PBMC were collected after post-infection and HIV-1 p24 antigen was determined by using ELISA. The data (mean \pm standard deviation) shown are representative of three independent experiments, each performed in triplicate.

Effect of heat on PAI-induced anti-HIV-1 activity: We tested whether the induction of anti-HIV-1 activity by PAI-stimulated PBMC is affected by heat. Pretreatment of culture fluids of PAI-stimulated PBMC at $56^{\circ} \mathrm{C}$ for $30 \mathrm{~min}$ did not affect antiviral activity (Fig. $2 \mathrm{~A})$. However, when the culture fluids were pre-heated at $100^{\circ} \mathrm{C}$ for $10 \mathrm{~min}$., the anti-HIV-1 activity was eliminated (Fig. 2B). Thus, these results demonstrate that the PAI-induced anti-HIV-1 activity is sensitive to heat.

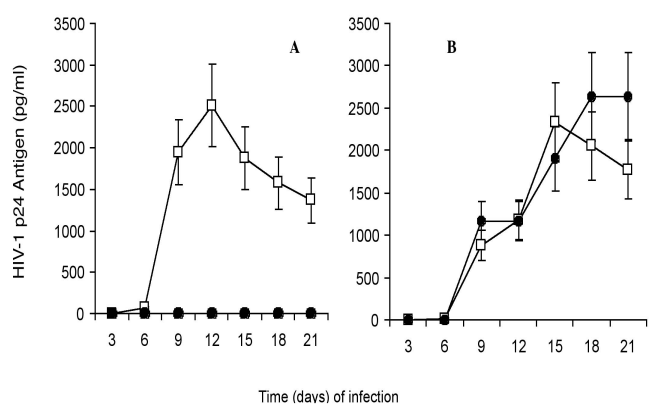

Fig. 2: Test of inhibition of PAI-stimulated anti-HIV-1activity on acutely infected PBMC from healthy volunteers with HIV$1_{\mathrm{SF} 2}$ virus $\left(1,000 \mathrm{TCID}_{50} / 10^{5}\right.$ cells $)$ cultured with heated culture fluids from PBMC stimulated with PAI (circles) or unstimulated (open squares). Culture fluids heated at $56^{\circ} \mathrm{C}$ for $30 \mathrm{~min}$. (A) and $100^{\circ} \mathrm{C}$ for $10 \mathrm{~min}$. (B). Supernatants derived from HIV-1 infected PBMC were collected after post-infection and HIV-1 p24 antigen was determined by using ELISA. The results, expressed as mean \pm standard deviation, are representative of three independent experiments, each performed in triplicate. The cell viability of HIV-1 infected PBMC ranged from 80 to $95 \%$. 
PAI-stimulated anti-HIV-1 activity is associated with the modulation of cytokines and $\beta$-chemokines and is dependent on the patient's CD4:CD8 ratio: To further characterize the inhibition of HIV-1 replication by PAI-stimulated culture fluids, we tested the effect of these culture fluids on the production of cytokines (IL-2, IL-4, IL-10, IFN- $\gamma$ ) and $\beta$-chemokines (MIP-1 $\alpha$, MIP-1 $\beta$, and RANTES) that have been shown to be involved in the modulation of HIV-1 replication ${ }^{[46-48]}$. Anti-HIV-1 activity was observed in the culture fluids from PAI-stimulated PBMC taken from HIV-infected patients with various CD4:CD8 ratios (Fig. 3A). PAI-induced anti-HIV activity was totally dependent on the HIV-infected patient's CD4:CD8 ratio, since it decreased as the CD4:CD8 ratio of the patients approached 0.6 and was significantly diminished in cultures from patients with a ratio as low as 0.4 (Fig. 3A).
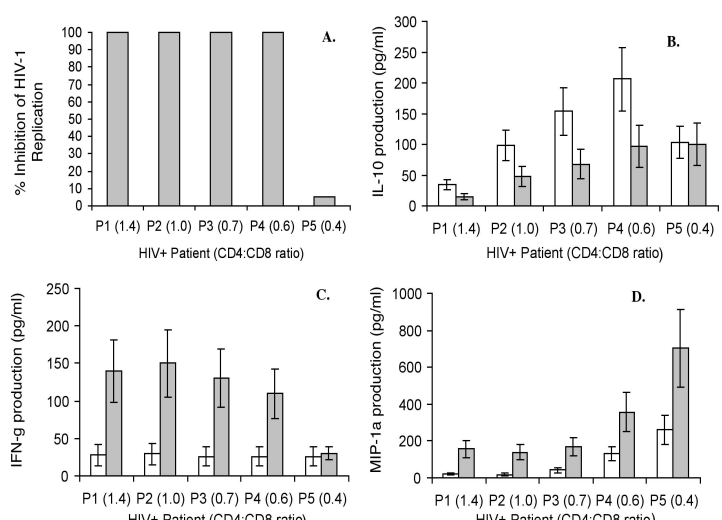

HIV+ Patient (CD4:CD8 ratio)
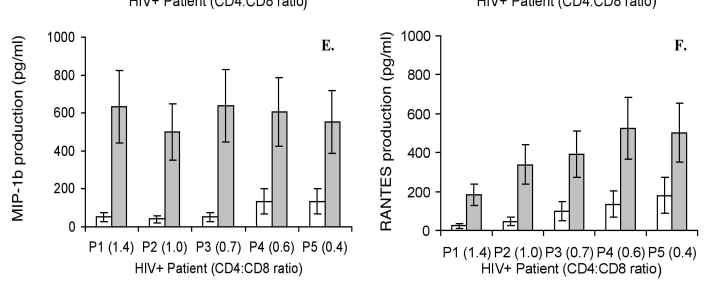

Fig. 3: Comparison of PBMC derived from five HIV-1 seropositive patients for PAI-stimulated inhibition of HIV$1_{\mathrm{SF} 2}$ replication (A) and IL-10 (B), IFN- $\gamma(\mathrm{C}), \mathrm{MIP}-\alpha(\mathrm{D})$, MIP-1 $\beta$ (E), and RANTES (F) production. Open bars represent culture fluid from unstimulated PBMC (control) whereas solid bars represent culture fluids from PAIstimulated PBMC. Each patient had a different CD4:CD8 ratio. CD4:CD8 ratios ranged from 0.6 to 1.4 in patients who had a viral load less than 400 RNA copies/ml and asymptomatic, whereas the patient with a CD4:CD8 ratio of 0.4 had a viral load of 358,330 RNA copies $/ \mathrm{ml}$ and symptomatic. Cytokine and $\beta$-chemokine production was measured using ELISA. The results, expressed as mean \pm standard deviation, are representative of three independent experiments, each performed in triplicate.
The levels of cytokines and $\beta$-chemokines were altered by the exposure of culture fluids derived from PAI-stimulated PBMC (Fig. 3B-3F). IL-10 production was significantly inhibited to $43-45 \%$ in supernatants in which HIV-1 replication was completely inhibited (Fig. 3B). A significant induction of the levels of IFN- $\gamma$ to $75-80 \%$, MIP- $1 \alpha$ to $60-85 \%$, MIP- $1 \beta$ to $75-90 \%$, and RANTES to $70-85 \%$ (Fig. 3C-3F) occurred, but IL-2 and IL-4 production was not affected (data not shown).

\section{DISCUSSION}

In the present study, we show that polyantigenic immunomodulator (PAI)-stimulated PBMC and CD8+ T-cells produce a soluble factor(s) that inhibits HIV-1 replication. This induced anti-HIV-1 soluble factor(s): (a) blocks the replication of both R5- and X4-tropic viruses, (b) is instable at high temperature, and (c) is produced by both CD8+ T-cells and non-CD8+ T-cells. This PAI-induced anti-HIV-1 activity differs in these properties from those found for CAF ${ }^{[16]}$ and $\beta$ chemokines ${ }^{[15]}$, the two most extensively studied antiHIV-1 soluble factors.

Another soluble anti-HIV factor(s) stimulated by influenza virus has been reported to be different from those of CAF and the $\beta$-chemokines ${ }^{[49,50]}$. The antiHIV-1 activity of the described novel agent: (a) inhibits replication prior to reverse transcription in PBMC of different HIV-1 isolates (R5 and X4) from HIV negative or positive donors, (b) can be generated by CD4- or CD8-depleted PBMC, and (c) appears to be partially induced by IFN- $\alpha$ but not by IFN- $\gamma$, IFN- $\beta, \beta-$ chemokines (MIP-1 $\alpha$, MIP-1 $\beta$, and RANTES) or IL-16 [50]. Although, the experimental design that led to these latter findings differs from our protocol, this data is somewhat consistent with the results reported here. However, the inducing agent (PAI) employed in the present study is antigenically more complex since, in addition to the influenza virus vaccine, it contains a multi-bacterial component. Nevertheless, the possibility that Pinto's anti-HIV-1 soluble factor(s) is similar to at least the one described in this study cannot be overruled.

We have shown that both PAI-stimulated PBMC and CD8+ T-cells from HIV-1 infected patients can produce HIV-1 soluble factor(s). Although PAIstimulated CD8+ T-cells can generate anti-HIV-1 activity, this antiviral activity was not as powerful as the one generated by PAI-stimulated PBMC suggesting that not solely CD8+ T-cells are needed to obtain a complete inhibition of HIV-1 replication. In contrast to $\mathrm{CAF}$, it is clear that the production of this antiviral 
soluble factor(s) is not limited to CD8+ T-cells. Thus, identification of specific immune cells that generate this antiviral activity is needed.

It is important to mention that we compared culture fluids from PAI-stimulated PBMC with culture fluids from unstimulated PBMC and these showed no detectable HIV-1 p24 antigens, suggesting that the addition of culture fluids to the HIV-1 inhibition assay did not contribute to the increased levels of HIV-1 p24 antigens observed in this assay. In addition, we also showed that when the culture fluids from PAIstimulated PBMC were pre-heated at $100^{\circ} \mathrm{C}$ for 10 min., they lost the capability to inhibit HIV-1 replication. Since it has been shown that CAF resists this heat treatment ${ }^{[51]}$, therefore, the antiviral activity mediated by PAI-stimulated culture fluids is different from that produced by CAF.

The PAI-induced anti-HIV-1 activity may be due to the modulation of antiviral cytokine/ $\beta$-chemokine production, or to a yet unidentified anti-HIV-1 putative factor or to a combination of various anti-HIV-1 soluble factors. We demonstrate that this PAI-induced soluble factor(s) is produced by PAI-stimulated PBMC from HIV-1 infected patients with CD4:CD8 ratios over 0.6 and favors the upregulation of the antiviral $\beta$ chemokines (MIP-1 $\alpha$, MIP-1 $\beta$, and RANTES) and IFN- $\gamma$, whereas it downregulates IL-10. Moreover, the induced anti-HIV-1 activity disappeared in spite of the presence of high levels of $\beta$-chemokines, suggesting that the presence of other soluble factor (s) may be responsible for the anti-HIV-1 activity. In contrast, in those experiments in which the antiviral activity disappeared, the levels of IFN- $\gamma$ were significantly inhibited, suggesting that IFN- $\gamma$ is necessary for the induction of antiviral activity.

We suggest that the inability of culture fluids from PAI-stimulated PBMC of HIV-1 infected patients with a CD4:CD8 ratio below 0.6 to suppress HIV-1 replication and modulate cytokines/ $\beta$-chemokines could be due to: (a) the dramatic reduction in helper CD4+ Tcells to sustain or generate new immune responses; (b) to the excessive increase in anergic, dysfunctional and/or suppressor CD8+ T-cells; (c) to the inability to build a regulatory cytokine and $\beta$-chemokine environment; or (d) to the inability to produce an antiHIV-1 soluble factor(s).

In conclusion, the PAI-induced factor (s) is: (a) produced by both CD8+ T cells and PBMC; (b) is active against the HIV-1 ${ }_{\mathrm{SF} 2}$, a dual-tropic (R5X4) strain; (c) is not restricted by MHC; (d) is heat-labile; (e) is capable of suppressing HIV-1 replication in an environment containing high levels of IFN- $\gamma$ and $\beta$ chemokines, but low concentrations of IL-10, and; (f) is induced predominantly in culture fluids from PAIstimulated PBMC from HIV-1 infected patients with CD4:CD8 ratios over 0.6.

Recently, we have implemented the use of proteomic and mass spectrometry technology to isolate, identify, and further characterize the soluble anti-HIV-1 factor (s) induced by PAI. Our preliminary results suggest that PAI induces an intracellular inhibitor of the HIV-1 Tat protein (unpublished data). This is important since Tat plays a central role in sustaining a high level of HIV-1 replication. Recently, it has been reported several compounds that selectively inhibit the functions of Tat suppressing HIV-1 replication ${ }^{[52]}$. We believe that the discovery of these naturally occurring antiHIV-1 compounds could lead to the development of a safe, inexpensive, and effective immunotherapeutic strategy, which, combined with HAART, could be an innovative way of treating HIV-1 infections or perhaps delaying HIV-1 disease progression.

\section{ACKNOWLEDGEMENT}

Special recognition is given to Drs. Angel $\mathrm{M}$. Marchand and Julio I. Colón for the original idea of using PAI, in its complete form as an immunomodulator. We are also grateful to Dr. Gary Williams for his help editing this paper. This work was supported by NIH-RCRIIP20RR11108, NIHRCMIG12RR03035, and NIDA grants RO1DA015628, RO1-DA012366, RO1-DA014218, and RO1-DA021537.

\section{REFERENCES}

1. UNAIDS. Report on the global AIDS epidemic http://www.unaids.org/en/hiv_data/2006 globalreport

2. Aiuti, F. and I. Mezzaroma, 2006. Failure to reconstitute $\mathrm{CD} 4+\mathrm{T}$-cells despite suppression of HIV replication under HAART. AIDS Rev., 8(2): 88-97.

3. Akerele, T., G. Galatowicz, C. Bunce, V. Calder, W.A. Lynn, and S. Lightman, 2006. Normalized CD8+ but not CD4+ lymphocyte IL-2 expression is associated with early treatment with highly active antiretroviral therapy. Clin. Immunol., 121(2):191-197.

4. Le Guillou-Guillemette, H., G. Renier, B. Vielle, P. Abgueguen, J.M. Chennebault, F. Lunel, and C. Payan, 2006. Immune restoration under HAART in patients chronically infected with HIV-1: diversity of $\mathrm{T}, \mathrm{B}$, and $\mathrm{NK}$ immune responses. Viral Immunol., 19(2): 267-276. 
5. Verheggen, R.., 2003. Immune restoration in patients with HIV infection: HAART and beyond. J Assoc Nurses AIDS Care, 14(6):76-82.

6. Gotch, F., 2005. Therapeutic vaccines and immunotherapy revisited. J. HIV Ther., 10(3): 4850 .

7. Gahery, H., S. Figueiredo, C. Texier, S. PouvelleMoratille, L. Ourth, C. Igea, M. Surenaud, J.G. Guillet, and B. Maillere, 2007. HLA-DR-restricted peptides identified in the Nef protein can induce HIV type 1-specific IL-2/IFN-gamma-secreting CD4+ and CD4+/CD8+ $\mathrm{T}$ cells in humans after lipopeptide vaccination. AIDS Res. Hum. Retroviruses, 23(3):427-437.

8. Barnett, S.W., I.K. Srivastava, J.B. Ulmer, J.J. Donnelly, and R. Rappuoli, 2005. Development of V2-deleted trimeric envelope vaccine candidates from human immunodeficiency virus type 1 (HIV1) subtypes B and C. Microbes Infect., 7(14): 1386-1391.

9. Burgers, W.A., J.H. van Harmelen, E. Shephard, C. Adams, T. Mgwebi, W. Bourn, T. Hanke, A.L. Williamson, and C. Williamson, 2006. Design and preclinical evaluation of a multigene human immunodeficiency virus type 1 subtype C DNA vaccine for clinical trial. J. Gen. Virol., 87(Pt 2): 399-410.

10. Erfle, V., F.D. Goebel, C.A. Guzman, and R. Le Grand, 2005.Vaccines based on Nef and on Nef/DeltaV2 Env. Microbes Infect., 7(14):14001404.

11. Graham, B.S., R.A. Koup, M. Roederer, R.T. Bailer, M.E. Enama, Z. Moodie, J.E. Martin, M.M. McCluskey, B.K. Chakrabarti, L. Lamoreaux, C.A. Andrews, P.L. Gomez, J.R. Mascola, G.J. Nabel., 2006. Phase 1 safety and immunogenicity evaluation of a multiclade HIV-1 DNA candidate vaccine. J Infect Dis., 194(12):1650-1660.

12. Horton, H., C. Havenar-Daughton, D. Lee, E. Moore, J. Cao, J. McNevin, T. Andrus, H. Zhu, A. Rubin, T. Zhu, C. Celum, and M.J. McElrath, 2006. Induction of human immunodeficiency virus type 1 (HIV-1)-specific T-cell responses in HIV vaccine trial participants who subsequently acquire HIV-1 infection. J. Virol., 80(19): 9779-9788.

13. Ondondo, B.O., H. Yang, T. Dong, K. di Gleria, A. Suttill, C. Conlon, D. Brown, P. Williams, S.L. Rowland-Jones SL, T. Hanke, A.J. McMichael, and L. Dorrell, 2006. Immunisation with recombinant modified vaccinia virus Ankara expressing HIV-1 gag in HIV-1-infected subjects stimulates broad functional CD4+ T cell responses. Eur. J. Immunol., 36(10): 2585-2594.
14. Tavel, J.A., J.E. Martin, G.G. Kelly, M.E. Enama, J.M. Shen, P.L. Gomez, C.A. Andrews, R.A. Koup, R.T. Bailer, J.A. Stein, M. Roederer, G.J. Nabel, and B.S. Graham, (2007). Safety and immunogenicity of a Gag-Pol candidate HIV-1 DNA vaccine administered by a needle-free device in HIV-1-seronegative subjects. J. Acquir. Immune Defic. Syndr., 44(5):601-605.

15. DeVico, A.L. and R.C. Gallo. 2004, Control of HIV-1 infection by soluble factors of the immune response. Nat. Rev. Microbiol. 2(5): 401-413.

16. Levy, J.A., 2003. The search for the CD8+ cell anti-HIV factor (CAF). Trends Immunol. 24(12): 628-632.

17. Levy, J.A., 2006. HIV pathogenesis: knowledge gained after two decades of research. Adv. Dent. Res., 19(1):10-16.

18. Walker, C.M., A.L. Erickson, F.C. Hsueh, and J.A. Levy, 1991. Inhibition of human immunodeficiency virus replication in acutely infected CD4+ cells by CD8+ cells involves a noncytotoxic mechanism. J. Virol. 65(11): 59215927.

19. Walker, C.M., D.J. Moody, D.P. Stites, and J.A. Levy, 1986. CD8+ lymphocytes can control HIV infection in vitro by suppressing virus replication. Science 234(4783): 1563-1566.

20. Mackewicz, C. and J.A. Levy, 1992. CD8+ cell anti-HIV activity: nonlytic suppression of virus replication. AIDS Res Hum Retroviruses 8(6): 1039-1050.

21. Mackewicz, C.E., D.J. Blackbourn, and J.A. Levy, 1995. CD8+ T cells suppress human immunodeficiency virus replication by inhibiting viral transcription. Proc. Natl. Acad. Sci. USA 92(6): 2308-2312.

22. Cocchi, F., A.L. De Vico, A. Garzino-Demo, S.K. Arya, R.C. Gallo, and P. Lusso, 1995. Identification of RANTES, MIP- $1 \alpha$, MIP-1 $\beta$ as the major HIV-suppressive factors produced by CD8+ T-cells. Science 270:1811-1815.

23. Mackewicz, C.E., E. Barker, and J.A. Levy, 1996. Role of beta-chemokines in suppressing HIV replication. Science 274(5291): 1393-1395.

24. Altenburg, J.D., H.E. Broxmeyer, Q. Jin, S. Cooper, S. Basu, and G. Alkhatib, 2007. A Naturally Occurring Splice Variant of CXCL12/Stromal Cell-Derived Factor 1 is a potent HIV-1 inhibitor with weak chemotaxis and cell Survival activities. J. Virol., (in press). 
25. Rugeles, M.T., C.M. Trubey, V.I. Bedoya, L.A. Pinto, J.J. Oppenheim, S.M. Rybak, and G.M. Shearer, 2003. Ribonuclease is partly responsible for the HIV-1 inhibitory effect activated by HLA alloantigen recognition. AIDS 17(4): 481-486.

26. Alfano M, N. Sidenius, B. Panzeri, F. Blasi, and G. Poli, 2002. Urokinase-urokinase receptor interaction mediates an inhibitory signal for HIV-1 replication. Proc. Natl. Acad. Sci. U S A. 99(13): 8862-8867.

27. Van Drenth, C., A. Jenkins, L. Ledwich, T.C. Ryan, M.V. Mashikian, W. Brazer, D.M. Center, and W.W. Cruikshank, 2000. Desensitization of CXC chemokine receptor 4 , mediated by IL$16 / C D 4$, is independent of p56lck enzymatic activity. J. Immunol. 165(11): 6356-6363.

28. Geiben-Lynn R, N. Brown, B.D. Walker, and A.D. Luster. 2002. Purification of a modified form of bovine antithrombin III as an HIV-1 CD8+ T-cell antiviral factor. J. Biol. Chem. 277(44): 4235242357.

29. Chang, T.L., F. Francois, A. Mosoian, and M.E. Klotman, 2003. CAF-mediated human immunodeficiency virus (HIV) type 1 transcriptional inhibition is distinct from alphadefensin-1 HIV inhibition. Virol. 77(12): 67776784.

30. Horuk, R., J. Hesselgesser, Y. Zhou, D. Faulds, M. Halks-Miller, S. Harvey, D. Taub, M. Samson, M. Parmentier, J. Rucker, B.J. Doranz, and R.W. Doms, 1998. The CC chemokine I-309 inhibits CCR8-dependent infection by diverse HIV-1 strains. J. Biol. Chem. 273(1): 386-391.

31. Geiben-Lynn, R., M. Kursar, N.V. Brown, M.M. Addo, H. Shau, J. Lieberman, A.D. Luster, and B.D. Walker, 2003. HIV-1 antiviral activity of recombinant natural killer cell enhancing factors, NKEF-A and NKEF-B, members of the peroxiredoxin family. J. Biol. Chem. 278(3): 15691574.

32. Moriuchi, H., M. Moriuchi, C. Combadiere, P.M. Murphy, and A.S. Fauci, 1996. CD8+ T-cellderived soluble factor(s), but not beta-chemokines RANTES, MIP-1 alpha, and MIP-1 beta, suppress HIV-1 replication in monocyte/macrophages. Proc Natl Acad Sci U S A. 93(26): 15341-15345.

33. Montaner, L.J., R.T. Bailer, and S. Gordon, 1997. IL-13 acts on macrophages to block the completion of reverse transcription, inhibit virus production, and reduce virus infectivity. J. Leukoc. Biol. 62(1): 126-132.
34. Bovolenta, C., A.L. Lorini, B. Mantelli, L. Camorali, F. Novelli, P. Biswas, and G. Poli, 1999. A selective defect of IFN-gamma- but not of IFNalpha-induced JAK/STAT pathway in a subset of U937 clones prevents the antiretroviral effect of IFN-gamma against HIV-1. J. Immunol. 162(1): 323-330.

35. Pal, R., A. Garzino-Demo, P.D. Markham, J. Burns, M. Brown, R.C. Gallo, and A.L. DeVico, 1997. Inhibition of HIV-1 infection by the betachemokine MDC. Science 278(5338): 695-698.

36. Patterson, B.K., H. Behbahani, W.J. Kabat, Y. Sullivan, M.R. O'Gorman, A. Landay, Z. Flener, N. Khan, R. Yogev, and J. Andersson, 2001. Leukemia inhibitory factor inhibits HIV-1 replication and is upregulated in placentae from nontransmitting women. J. Clin. Invest. 107(3): 287-294.

37. Dang, Y., X. Wang, W.J. Esselman, and Y.H. Zheng, 2006. Identification of APOBEC3DE as another antiretroviral factor from the human APOBEC family. J. Virol., 80(21):10522-10533.

38. Towers, G.J., 2007. The control of viral infection by tripartite motif proteins and cyclophilin A. Retrovirology, 4(1):40.

39. Colón, J.I., A.M. Marchand, A. Roman-Franco, and E.A. Santiago-Delpin, 1981. Immunotherapeutic effect of a polyantigenic vaccine in animal tumor models. Bol. Assoc. Med. P.R. 73:162-164.

40. Rios-Olivares, E.O., Z.M. Orraca, and J.I. Colón, 1986. Synergistic anti-tumor effect of an immunopotentiator (PAI) and an inhibitor of $\mathrm{T}$ suppressor (cimetidine), in Viruses, Immunity and Immunodeficiency. Editors: Plenum Publishing Corporation. pp. 333-336.

41. Colón, J.I., A.M. Marchand, M.T. Rodriguez, and D. Valldejuli, 1982, Stimulation of phytohemagglutinin blast transformation in cancer patients by polyantigenic vaccine. $8^{\text {th }}$ International convocation of Immunology, the Ernest Witebsky Center for Immunology, State University of New York at Buffalo, abstract no. 52.

42. Colón, J.I., A.M. Marchand, and G. Encarnacion, 1990. The use of polyantigenic immunomodulator in the management of patients infected with human immunodeficiency virus (HIV). J. Immunol. Immunopharmacol. 10(4): 133.

43. Colón, J.I., G. Encarnación, M.R Ortiz-Santini, M.T. Rodríguez-Malavé, E.A. Santiago-Delpín, and A.M. Marchand, 1997. Survival and quality of life in HIV-positive patients treated with a polyantigenic immunomodulator. P.R. Health Sci. J., 16(1): 9-14. 
44. Rios, Z., E.O. Rios-Olivares, M.I. Garcia, C. De Leon, L.M. Guzman, W. Rodriguez, D. Romero, and R. Hunter, 1995. Changes in viral expression and cytokine profile induced by a polyantigenic immunomodulator in $\mathrm{HIV}$-infected peripheral blood mononuclear cells. Cellular and Molecular Biology. 41(Suppl. I): S93-S101.

45. Vila, L.M., E.O. Rios-Olivares, S. Vila, Z. Ríos, E. Rivera, R. Robles, J.C. Reyes, and X. Castillo, 1997. Correlation of the suppressive activity of a biological response modifier on the proliferation of peripheral blood mononuclear cells and the reduction of HIV titer. Cellular and Molecular Biology 43(7): 981-988.

46. Garzino-Demo, A., 2007. Chemokines and defensins as HIV suppressive factors: an evolving story. Curr. Pharm. Des., 13(2):163-172.

47. Suresh, P. and A. Wanchu, 2006. Chemokines and chemokine receptors in HIV infection: role in pathogenesis and therapeutics. J. Postgrad. Med., 52(3): 210-217.
48. Alfano, M. and G. Poli, 2005. Role of cytokines and chemokines in the regulation of innate immunity and HIV infection. Mol. Immunol., 42(2):161-182.

49. Pinto, L.A., G.M. Shearer, and V. Blazevic, 2000. Immune-based approaches for control of HIV infection and viral-induced immunopathogenesis. Clin. Immunol. 97(1): 1-8.

50. Pinto, L.A., V. Blazevic, B.K. Patterson, C. Mac Trubey, M.J. Dolan, and G.M. Shearer, 2000. Inhibition of human immunodeficiency virus type 1 replication prior to reverse transcription by influenza virus stimulation. J. Virol. 74(10): 4505-4511.

51. Levy, J.A., C.E. Mackewicz, and E. Barker, E., 1996. Controlling HIV pathogenesis: the role of the noncytotoxic anti-HIV response of CD8+ T cells. Immunol. Today 17(5): 217-224.

52. Baba, M., 2006. Recent status of HIV-1 gene expression inhibitors. Antiviral Res. 71(2-3):301306. 